\section{Football and altitude: a FIFA vision}

\section{Michel D'Hooghe}

In the world of football, the visiting national teams are sometimes confronted with different environmental conditions: heat, cold and different relative humidities are good examples, but the most important one is the practice of football at altitude.

In 2007, the Medical Committee of Federation Internationale de Football Association (FIFA) had organised a consensus meeting, with 12 international scientists, who have performed their own research in this respect. The consensus provided recommendations and guidelines for training and playing at different altitude, taking note that, due to the surcharged football calendar, a long adaptation period is not always possible.

Federation Internationale de Football Association (FIFA) Medical Commission and FIFA Medical Assessment and Research Centre (F-MARC), Zurich, Switzerland

Correspondence to Dr Michel D'Hooghe, Federation Internationale de Football Association (FIFA) Medical Commission and FIFA Medical Assessment and Research Centre (F-MARC), Langerei, 71, 8000 Brugge, Belgium; michel.dhooghe@skynet.be
The game of football proposes anaerobic and aerobic activities, and requires physical, technical and tactical skills. These skills depend on the training exercises and on intact cognitive functions and coordination, as a result of a neuromuscular mechanism. Playing football at altitude undoubtedly influences those skills and determines the outcome of crucial match situations.

FIFA was grateful and honoured to participate to the high-level consensus meeting, organised in 2013 by the Aspetar Clinic of Doha, under the scientific guidance of Dr Olivier Girard. Aspetar, one FIFA accredited Medical Centre of Excellence (FIFA Medical Assessment and Research Centre, F-MARC), was indeed the adequate and optimal place to reach a new consensus, based on the scientific observations from the last 6 years. Enormous efforts have been accomplished to recreate altitude conditions: 25 hypoxic normobaric rooms were fully equipped together with hypoxic chambers and a specially constructed tunnel, $45 \mathrm{~m}$ long creates ideal conditions for training in hypoxia.
It was, for the medical leadership of FIFA, an unique occasion to confront their views with the most recent scientific information on the latest strategies for developing peak performance and optimising the 'altitude dose'. The presentations and discussions that took place at the Aspetar meeting are published in this supplement.

\section{Competing interests None.}

Provenance and peer review Not commissioned; internally peer reviewed.

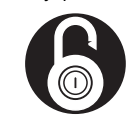

\section{OPEN ACCESS}

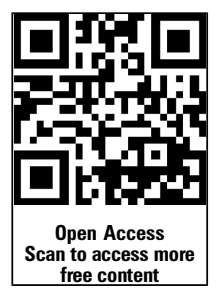

Open Access This is an Open Access article distributed in accordance with the Creative Commons Attribution Non Commercial (CC BY-NC 3.0) license, which permits others to distribute, remix, adapt, build upon this work non-commercially, and license their derivative works on different terms, provided the original work is properly cited and the use is non-commercial. See: http:// creativecommons.org/licenses/by-nc/3.0/

To cite D'Hooghe M. Br J Sports Med 2013;47:i1. Accepted 21 August 2013

Br J Sports Med 2013;47:i1. doi:10.1136/bjsports-2013-093006 